DOI 10.37882/2223-2982.2021.01-2.02

\title{
РОЛЬ РУССКОЙ ДЕТСКОЙ ЛИТЕРАТУРЫ В ПРЕПОДАВАНИИ РКИ (ДО УРОВНЯ А2+)
}

\section{THE ROLE OF RUSSIAN CHILDREN'S LITERATURE IN TEACHING RFL (UP TO LEVEL A2 +)}

\section{E. Astashchenko} M. Syrova

Summary: This article explores and improves the effective use of materials from children's fiction texts in Russian language studies to the level of A2 + in order to develop reading skills, and form the linguistic and cultural competence of students. The selection criteria for works of fiction are highlighted on the basis of the state standard for Russian as a foreign language (basic level), according to which the reader is obliged not only to "cover" the content of the text as a whole, but also to be able to choose the correct reading strategy depending on the attitude. Thus, when studying reading, the student must be able to determine the topic of the text; to understand its main idea, as well as, which is important, and additional information contained in details, including pictorial and expressive means, characteristic of a given style of text and type of speech. With the type of control strategies, one can correlate such strategies as isolating the main idea and searching for the necessary information, and with the type of execution strategies - determining the meanings of words with the help of text, contextual guessing, fixing attention on details. Guided by such criteria for the selection of texts as the artistic method (preferably realism), grammatical norms and subject-thematic correspondence to the course program, it is possible to supplement the existing and well-proven teaching materials for several decades with texts of Russian literature for children and youth, facilitating the socialization of a foreigner, as well as improving his culture and forming his linguistic and cultural competence.

Keywords: RCT, basic level, reading, strategies, children's literature, young-adult-literature, style.
Астащенко Елена Васильевна

К.филол.н., старший преподаватель, Национальный исследовательский Московский государственный строительный университет gedda@inbox.ru

Сырова Мария Михайловна

Преподаватель, Национальный исследовательский Московский государственный строительный университет mariya.m.syrova@mail.ru

Аннотация: В данной статье исследуется и совершенствуется эффективное использование материалов текстов детской художественной литературы на уроках РКИ до уровня А2+ с целью развития навыков чтения, формирования лингвострановедческой компетенции студентов. Критерии отбора произведений художественной словесности выделены на базе государственного стандарта по русскому языку как иностранному (базовый уровень), согласно которому читающий обязан не только в целом «охватить» содержание текста, но и уметь выбрать верную стратегию чтения в зависимости от установки. Так, при изучающем чтении студент должен уметь определить тему текста; понять его основную идею, а также, что немаловажно, и дополнительную информацию, содержащуюся деталях, в том числе изобразительно-выразительных средствах, характерных для данного стиля текста и типа речи. С типом стратегий контроля можно соотнести такие стратегии, как вычленение главной мысли и поиск необходимой информации, а с типом стратегий исполнения - определение значений слов с помощью текста, контекстную догадку, фиксацию внимания на деталях. Руководствуясь такими критериями отбора текстов, как художественный метод (предпочтительно реализм), грамматические нормы и предметно-тематическое соответствие программе курса, можно дополнять существующие и отлично зарекомендовавшие себя на протяжении нескольких десятилетий УМК текстами русской словесности для детей и юношества, облегчая социализацию иностранца, а также совершенствуя его культуру и формируя его лингвострановедческую компетенцию.

Ключевые слова: РКИ, базовый уровень, чтение, стратегии, детская литератуpa, young-adult-literature, стиль.

содержания; - изменять стратегию чтения в зависимости от установки (при встрече с информацией, требующей изучающего чтения); - определить тему текста; понять его основную идею; - понять как основную, так и дополнительную информацию, содержащуюся в тексте, с достаточной полнотой, точностью и глубиной.» [3, с. 9]. Таким образом, иностранные студенты, обучающиеся на базовом уровне, должны достаточно хорошо понимать содержание и основную идею читаемого текста, уметь анализировать текст и выбирать подходящую стратегию чтения, не только правильно воспринимать общую идею и информацию, но и замечать детали. Выбирать стратегии чтения - значит, быть с ними знакомым и уметь 
применять нужную стратегию, в том числе к иноязычному произведению. Целесообразное извлечение информации при чтении и использование этой информации - ключевые умения, которыми должен овладеть иностранный обучающийся на начальном этапе обучения. Вот почему для развития данного умения нужно уже на элементарном и базовом этапах обучать стратегиям чтения. Использование стратегий чтения поможет обучающимся глубже понимать содержание текста при чтении, анализировать информацию и строить речь с учётом полученной информации, то есть синтезировать новое самостоятельное высказывание относительно прочитанного.

Материал текстов художественной детской литературы представляет особую ценность, с точки зрения возможности использовать эти тексты для развития умений пользоваться стратегиями чтения на базовом уровне. Это связано с особенностями текстов, созданных для детей. Часто они имеют доступный для понимания сюжет, соответствующий уровень сложности лексики и грамматики. Кроме того, тематика текстов доступна для обучающихся на базовом уровне и созвучна тому, что изучается в основном курсе по программе. А это также является требованием к текстам, представленном в стандарте преподавания РКИ на базовом уровне: «Тематика текста актуальна для сферы повседневного общения, социально-культурной и учебной сфер» [3, с. 9]. Среди множества текстов детской художественной литературы можно подобрать те, которые отвечают данным требованиям. Именно благодаря чтению текстов, специально написанных для детей, иностранные студенты могут получить возможность не только читать аутентичные тексты доступного им уровня, но и прикоснуться к культуре, близкой и понятной носителям языка, а знакомство с лексикой, входящей в обиход ребенка, несомненно будет полезно для иностранца с практической точки зрения, поможет ему увереннее чувствовать себя в сфере повседневного общения. Детская литература также может соответствовать требованию стандарта относительно типа текста «сообщение, повествование, описание, а также тексты смешанного типа.» [3, с. 9]. Вид чтения, который должен использоваться на базовом уровне, согласно государственному стандарту преподавания РКИ для базового уровня, - это изучающее чтение, чтение с общим охватом содержания. [3, с. 9]. Обучение изучающему чтению направлено на развитие умения «максимально полно и точно извлечь из иностранного текста содержащуюся в нем информацию. В этом случае читающий предполагает, что ему придется впоследствии воспроизводить или использовать в той или иной форме полученную информацию, а это связано с осмыслением информации, ее интерпретацией, установкой на длительное запоминание (всей или части информации) уже в процессе чтения».[4, с. 7]. Как мы видим, изучающее чтение связано с извлечением, анализом и использо- ванием полученной из текста информации при чтении. Изучающее чтение можно соотнести со стратегиями чтения, которые направлены на поиск информации с целью дальнейшего её использования. Существуют различные классификации стратегий чтения. Л.Ю. Собинова описывает следующие типы стратегий чтения: «1) стратегии планирования; 2) стратегии исполнения; 3) стратегии контроля; 4) стратегии порождения» [5, с. 185]. С типом стратегий контроля можно соотнести такие стратегии, как вычленение главной мысли и поиск необходимой информации, а с типом стратегий исполнения - определение значений слов с помощью текста, контекстную догадку, фиксацию внимания на деталях. Именно эти стратегии - необходимость их разнообразия доказана коллегами [6, с. 82; 7, с. 139] - возможно развивать на материале текстов художественной литературы для детей, так они могут сочетать в себе с одной стороны доступность сюжета для понимания, а с другой - сложные для иностранцев лексические единицы, значение которых может быть раскрыто из контекста, знакомую тематику текста и новые детали знакомых понятий повседневной реальности.

При встрече с пересказом переводной литературы, например, «The Luncheon» С. Моэма в одном из лучших учебников по РКИ, иностранные студенты сразу же узнают английский рассказ (ведь английскому во всём мире также учат на его рассказах), что вызывает у них недоразумение и даже подозрение в плагиате, поэтому необходимо предварительное объяснение жанра «учебный текст». Адаптированные тексты русских классиков все равно часто остаются не вполне понятыми: например, адаптированный для базового уровня текст рассказа «Полотенце с петухом» М.А. Булгакова. Обращение же к детской литературе, у таких авторов, как Н.А. Костюк и Д. Филлипс (серия «Читаем без проблем»), к детской поэзии М.М. Нахабиной, В.Е. Антоновой, И.В. Курловой («Русский сезон») встречает понимание как на лексико-грамматическом, так и на содержательном уровне. Воспитание художественного вкуса взрослого человека на материале детской литературы нисколько не упрощает понимание иностранцем иной культуры, напротив, как говорил К.С. Станиславский: «Для детей нужно писать так же, как для взрослых, только еще лучше». Именно русская детская литература как нельзя лучше соответствует «манифесту» С.Я. Маршака: «Мы ищем той простоты, до которой надо подняться, а не той, до которой опускаются». Руководствуясь, не в последнюю очередь, стремлением сформировать у иностранных студентов грамматическую парадигматику и синтагматику, авторы пособий по РКИ предлагают тексты как знаменитых детских писателей (Г.М. Цыферов), так и незаслуженно забытых (О.Д. Шихзаманова), но популярных около полувека назад, что позволяет иностранцу прикоснуться к подлинному детству россиян разных поколений (в случае акцентирования лингвострановедческого компонента общеизвестность 
в среде носителей языка - фактор немаловажный). Оставляя за рамками вопрос о роли именно аутентичного материала в процессе изучения иностранного языка, можно вывести несколько причин внимания именно к детской литературе.

Критериями нашего отбора материала для чтения на базовом уровне будут 1) художественный метод; 2) грамматика; 3) предметно-тематическое соответствие программе курса.

Связь именно детской литературы с культурой и массмедиа несомненна. Колыбельные и потешки, мультфильмы и сценарии event-агентств для детей выходят далеко за пределы словесности и глубоко укорены в национальном сознании. Иностранец, начинающий знакомство со страной с детской литературы как бы не нарушит естественный ход социализации. Однако сказки и фантастическая литература, переводы которой становятся мировыми бестселлерами менее всего (за небольшим исключением, например, сказок Н.Н. Носова, который в рассказе «Шурик у дедушки», гордится бабушкой, «хоть и старенькой, а в колдовство не верящей», то есть преимущественно сохраняет трезвый реалистичный взгляд на социум) применимы на уровне владения языком A2+. Например, если скатерть-самобранку заменить на скатерть-«всёдавайку», чтобы снять энантиосемию, провоцирующую превратное толкование образа, то нарушится аутентичность; лучше, конечно, подбирать, например, к обстоятельству направления действия «на все четыре стороны» уже существующий в русских народных сказках эквивалент «иди туда - не знаю куда», но это не всегда возможно. Бьющий все рекорды бестселлер Д. Роулинг «Гарри Поттер» невозможен на невысоком уровне владения английским: если даже слово «soul» приходится смотреть в словаре, то, например, слово «horcruх» не будет понятно и со словарём и вместе со всеми остальными объектами фантастической реальности будет абсолютно утрачен сюжет и смысл романов, даже если безграничную палитру роулинговских эпитетов с неуловимыми переходами оттенков заменить словом «волшебный», а все её редкие глаголы движения простыми типа идти, лететь. То же наблюдение верно и для русских сказочных романов и повестей: Т.И. Александрова, бережно сохранившая для многих поколений детей, сказочный мир русской деревни, в повести «Домовёнок Кузька», населяет свой художественный мир такими персонажами, как Берёза Кургузенькая и Осина Трясушка, а также обставляет «потерянными вещицами», которые «где же ты в нынешних домах найдёшь», а иностранцу, помимо архаизмов и историзмов, ещё необходимо ознакомиться с реалиями современного быта другой страны и их названиями. Близкая к фантастике по художествен- ным приёмам и изобразительно-выразительным речевым средствам ирреалистическая литература ещё менее подходит для уроков РКИ. Если в фантастике может отражаться почти без искажений вполне нормальная внешняя действительность и герои играют не мячом ${ }^{1}$, а похожим предметом, который назван по-другому, то ирреалистическая литература и лингвистическими и экстралингвистическими способами уводит от реальности. Если каждое действие сопровождается ирреальным сравнением, то сразу теряются границы сюжета, хронотопа, композиции и идейно-тематического ядра - и начинают спорить между собой (и дезориентировать иностранца) мир, преподнесённый писателем как данность, и внутренний мир героя или автора (после косвенно связанного с будущим временем союза «как будто» или отягчённого имперфектом «будто бы», или сослагательного наклонения, выражающего ирреальную объективную модальность). Сумма всех словарных значений не даст понимания текста, потому что он должен восприниматься метафорически и при этом цельно (почти как идиома), поэтому не готовый к переносному смыслу и постижению внутренней формы произведения читатель не сможет расшифровать, раскодировать стилевую систему высшего порядка. Постмодерн, востребованный пособиями по обучению чтению на начальном РКИ, как раз таки менее всего подходит. Сложная языковая игра и децентрализация художественного мира излишни на том уровне восприятия текста читателем, когда он с трудом понимает и связывает прямую последовательность событий. Симулякр, предполагающий отсутствие референциальных отсылок, - приём неоправданный в глазах того, кто и так не представляет реалии иноземного быта, то есть референты. Зачем иностранцу излюбленные Л.С. Петрушевской анаколуфы, если и без них он ошибается в элементарной грамматике? Что касается чистой грамматики лингвистических сказок писательницы, то для иностранца с минимальным лексическим запасом и обычные слова, выходящие за пределы базового минимума, пока он не посмотрит их в словаре и не запомнит, имеют именно такой выхолощенный образ: телёнок и «бокрёнок» равно не соотносятся с окружающей действительностью. Зачем тратить время на запоминание вымышленного, если ещё не знаешь название существующих в природе вещей? Речевой паттерн в процессе изучения иностранного языка - это заученная как бы не членимая модель, а постмодернистская игра речевыми штампами концептуалистов, преподнесённая иностранцам, может нарушить и без того хрупкую коммуникацию. Представленное во многих пособиях по чтению творчеству Д.И. Хармса, несмотря на отсутствие постмодернистского засилия анаколуфов, как и английская традиция нонсенса, не может быть оценена по достоинству без должного знания языка. Например, в стихотворении «Врун» трид-

1 Однако вряд ли возможно не имея представления о гольфе, бейсболе и других популярных в англоязычном мире играх хоть как-нибудь вообразить себе роулинговский квидиш. 
цать сыновей без лингвострановедческого комментария по поводу российской демографии могут быть восприняты и как реалия, а «ещё туда-сюда» вовсе не как «более-менее правдоподобно», а в буквальном значении. Интересно, что конкретно представит себе иностранный читатель? Поэтика, стремящаяся к абсурдистской, не лучший способ обучения языку, хотя, конечно, читатель продвинутого уровня, начиная с уровня В1+, рекомендуемого для абитуриентов гуманитарных вузов, способен наслаждаться «завиральными, порой алхимничающими изобретателями-выдумщиками» (Е. Евтушенко). Реалистические произведения маленького объёма, событийные и фабульные (причём, чтобы фабула совпадала с сюжетом, а не расходилась, как в «Лёгком дыхании» И.А. Бунина, также многими рекомендованным для РКИ А2). Например, адекватно и с лингвистической и экстралингвистической пользой воспринимается проза Л.Н. Толстого: басни «Стрекоза и муравей», «Работницы и петух», «Собака и её тень», «Осёл в львиной шкуре», «Лев и мышь», а также многажды входившие в пособия по чтению на базовом уровне «Лгун» и «Отец и сыновья»; рассказы и «были» для детей классика - «Лев и собачка», «Птичка», «Косточка», «Котёнок», «Подкидыш», «Пожарные собаки», «Акула», «Прыжок». Можно рекомендовать Рудольфио» и «Уроки французского» В.Г. Распутина (в сокращённом и минимально адаптированном виде), в отличие от других талантливых «деревенщиков» не перенасытивший прозу диалектизмами, просторечиями, идиомами, пословицами и поговорками, но сохранивший важную для иностранца аутентичность русского языка. Из писателей, творивших преимущественно для детей, конечно, подходит для РКИ В.Ю. Драгунский, отрывок рассказа которого «Что любит Мишка» (с очень пригодившимся для РКИ повтором конструкций с винительным падежом и модальных глаголов с инфинитивом) входит в самый авторитетное УМК по РКИ. Проза В.А. Осеевой «Синие листья», «Труд согревает», «Случай», «Сыновья», «Обидчики», «Просто старушка», «На катке», «Вырванный лист», «Просто так» читается почти без словаря и с интересом в западной и восточной иностранной аудитории, легко пересказывается. Юмористические рассказы Прозу Г.И. Горина («Ёжик») и Б.С. Ласкина («Малыш»), уже вошедшую в корпус текстов для обучения чтению на уроках РКИ, можно дополнить рассказами других юмористов, такими как «Хвастуны» Л. Измайлова, сценариста журнала «Ералаш» С. Степанова — «Мелодия для кобры», «Лекарство от застенчивости», «Клуб экстрим», «Страхагент», «Праздник для души», «Сладкая работа», «Дверь». Рассказы звёзд эпохи модерна, Тэффи и А. Аверченко, несут такой отпечаток изысканной вычурности слога и символистской избыточности значений, и вместе с тем импрессионистской туманности стиля, что, конечно, их следует оставить для более высокого уровня владения языком. Например, в рассказе Аверченко «Предводитель Лохмачёв», во-первых, затрагиваются с декадентской резкостью вопросы расовой дискримина- ции и социальной несправедливости, без намёка на сегодняшнюю толерантность, а во-вторых, новенький в группе сверстников подросток именуется «Посторонний Мальчик», для иностранца это не символическая многозначность и не связь с индейской культурой, а в лучшем случае не имя и фамилия; пристальное в начале XX века внимание к психическим изломам также не прочитывается без определённого культурного опыта. В текстах для языковой практики желателен внешний конфликт с разрешением или логический сюжет (не случайно большое количество детективов выбрано методистами для изучения языков $[8$, с. 178]), чёткая хронология и стройная композиция, отсутствие аппроксимации, а вот открытый финал вполне возможен (он провоцирует послетекстовые вопросы и экстралингвистический материал для дискуссии, выходящей за рамки художественного мира). Б.С. Житков в статье 1933 года «Что нужно взрослым от детской книги» пишет, что главное - это главное, можно без деталей: «Нарисовал дом, трубу, а из трубы дым. Если в трубу не проходит дым, это не труба, а тумба <...> В быке главное - рога». Обилие подробностей, конечно, затрудняет чтение текста на уровне A2.

Вторая важная для процесса изучения РКИ особенность - лексика, грамматика и синтаксис: есть проза, в которой форма не упрощается, как в учебном тексте, а изначально простая. Для А2 хотелось бы сформировать корпус текстов со стилистически нейтральной, общеупотребительной лексикой, незамысловатым синтаксисом, с небольшим количеством идиом, фразеологизмов, звукоподражаний, междометий, хезитативов, без передачи спонтанной речи и имитации дефектов речи. Как отметил Житков, в детской литературе важен «схематизм, крепкий и смелый». Уроженцы Баку В.В. Голявкин и О.Д. Шихзаманова, возможно, из-за нахождения в поликультурном пространстве, где русский язык не был родным и единственным, излагают мысли чётко, ясными и доступными словами и используют предельно простой синтаксис (почти без инверсий), при этом не упрощают идеи и создают красочные образы (Голявкин по профессии художник и это способствует синтезу искусств). Не удивительно, что именно эти авторы наиболее популярны у составителей пособий по РКИ. Целью этого отбора является увеличение доли беспереводного чтения в процессе обучения языку, способы, задачи и приёмы достижения которого исследует М.Г. Даниелян [9, с. 76-78], продолжение формирования грамматической компетенции и решение первостепенных познавательно-коммуникативных задач. Можно подобрать тексты под каждую грамматическую тему основных учебников и под каждый паттерн, чтобы запоминать грамматику и лексику в контексте, а не в отрыве от жизни, и моделировать жизненную ситуацию, стимулируя как бы реальную коммуникацию даже в пространстве обучения онлайн. Например, в первом «рассказе про Петю и папу» Л.Д. Каминского повторяются конструкции можно+инфинитив 
и похож на, в рассказе В.В. Голявкина «Ёж» «что это?» и «где-здесь», в девятой главе автобиографической повести К.И. Чуковского «Серебряный герб» десятки раз повторяется предложный падеж в объектном значении, в сказке Т.Ш. Крюковой «Смелый кораблик» повторяются базовые вопросы и обиходные фразы «как зовут?», «что это?», «ты не боишься?», «что случилось?», «чей?», «желаю удачи», в сказке И.С. Рогалёвой «про ворону Матрёну и её друзей» повторяются глаголы купить, отдать, поменять, подарить, в рассказе Е. Елича «Встретила» все основные глаголы движения, во вступлении к повести Э.Н. Успенского «25 профессий Маши Филипенко» сложное предложение с придаточной ирреального условия (дети пишут сочинение на тему «Если бы я был»).

Третий критерий — предметно-тематическая организация материала в соответствии с выбранным основным учебником курса. Здесь можно задействовать механизм контекстной догадки, антиципации, прогнозирования сюжета... Целью данного отбора будет, конечно же, формирование лингвострановедческой компетенции студентов. Именно поэтому не стоит забывать о различии менталитетов. Русская литература для детей и особенно юношества (за исключением первого и последнего десятилетий XXв.) балансировала на грани между глубинной искренностью, а которой говорил князь Мышкин Ф.М. Достоевского («Ребенку можно всё говорить, - всё <...> От детей ничего не надо утаивать под предлогом, что они маленькие и что им рано знать») и откровенностью, которая порой может навредить, травмировать, развратить. Учитывая несовпадение западных и восточных взглядов на воспитание, современная русская и западная переводная литературы не представляют возможности работать с ними на РКИ. Несмотря на уважение к «сказкам» Л.С. Петрушевской, романам П.В. Санаева, в том числе «Похороните меня за плинтусом», с приближенными к живой спонтанной речи диалогами и всегда интригующими иностранцев перестроечными реалиями, и к романистике («Письма до полуночи» М. Сонина), адресованной подросткам, так называемой ҮA (уoung adult), не отстающей от «передовой» немецкой подростковой литературы типа «Скажи, Красная шапочка» Беате Терезы Ханика, «Tschick» («Гуд бай, Берлин!») Вольфганга Херрндорфа или французской («Умник» Мари-Од Мюрай), можно сказать, что любой их фрагмент шокирует восточную аудиторию и отвлечёт от изучения языка. Возможно, в определённой аудитории подобная литература спровоцировала бы плодотворную дискуссию, но на родном, а не изучаемом языке. Даже иронии и метафоры следовало бы избегать при выборе текстов для уровня A2, потому что виртуозное сравнение В.В. Маяковского «опляшет Иродиадой солнце землю - голову Крестителя» с творительным падежом в значении уподобления или тем более сравнение с привычным союзом «как» или метонимий с родительным части («лес рук») объяснить проще, чем идиомы («попасть впросак», «хоть кол на голове теши») и стёртые метафоры типа «кошки скебут», «как по маслу» или «как об стенку горох», то же касается синекдох («белое платье пело в луче» и «ты все та же - лес, да поле, / Да плат узорный до бровей» А.А. Блока). Даже сравнение из «Слова о полку Игореве» XII В. («Серым волком рыская <...> Старый Гзак на Дон бежит великий») можно понять самостоятельно из-за творительного падежа уподобления, а к житейскому рассказу А.П. Чехова «В вагоне» о зайцах, безбилетниках, которых родним с животным скорость бега, нужны комментарии (их, кстати, можно найти в «Дороге в России» в тексте «Метро»). То же можно заметить об обиходных обращениях «горе луковое», об иронии (как у Ф.М. Достоевского в «Записках из подполья», где герой называют слугу палачом, ср. «ядовитый человек» Захар у А.И. Гончарова), равно как не все русские студенты понимают в романе «Великий Гэтсби» Ф.С. Фицджеральда «Blessed precious!», а иногда и «my honey». Любые тропы, приёмы со скрытым сравнением в основе, тем более такой глобальный «перенос» без демонстрации или наличия первичного объекта или указания на референт в фантастике или постмодерне, лучше предлагать на более высоком уровне. Вплоть до уровня Advanced (C1) изучающий иностранный язык с большим трудом читает «между строк» и ориентируется на формально выраженные, грамматические показатели, нормы и лексические стандарты [10].

Согласуясь с выбранными критериями отбора и предметно-тематическим блокам курса русского языка как иностранного элементарного и базового уровня можно предлагать следующие произведения для разных типов чтения.

Нравственность и семья: Л. Воронкова «Что сказала бы мама?», О. Корниенко «Шаги за дверью», В. Сухомлинский «Самые ласковые руки», А. Параскевин «Материнская молитва», В.К. Железников «Голубая Катя».

Система образования в России: И.М. Пивоварова, М.В. Дружинина, Г. Остер («Мифы и легенды Велтон-парка», где в рассказе «Полезный портрет» почти полностью представлена система образования), А. Лисаченко («Правдивые истории про Митю Печёнкина»), отрывки из автобиографических, полудокументальных и потому не столь насыщенных «художественностью» (ирреальными сравнениями, вычурными образами, вымышленными ситуациями, языковыми играми и сюжетно-композиционными экспериментами, а также повествованием с подменой, мистификацией или множественностью фокализации) «школьных повестей» К. Чуковского («Серебряный герб») и М. Зощенко («Перед восходом солнца», где в рассказе «Хлорофилл» объясняется принцип поднятия руки для вопроса или ответа, не во всех странах существующий), В.К. Железников «Космонавт».

Великая Отечественная война: Л. Пантелеев «Но- 
венькая», «Честное слово», К.Г. Паустовский «Стальное колечко», Ю.И. Коваль «Вишня».

Русские традиции, обычаи, праздники: Тэффи «Земная радуга. Воспоминания» (рассказ «Нигде», Новый год) и «Блины» (Масленица), С.Г. Георгиев «Как я спас Деда Мороза», Е. Елич «Встретила» (Пасха), В.К. Железников «Три ветки мимозы».

Природа России: Г.Я. Снегирёв «Обитаемый остров», «Лампанидус», «Скворец», «Чудесная лодка», «В пустыне», А.А. Федоров-Давыдов «Похождения Мурзилки», Е.Е. Горбунова-Посадова (рассказы о животных, о сезонах), С.Г. Козлов «Правда, мы будем всегда?».

Таким образом, подбирая верные стратегии на скру- пулёзно отобранном материале можно эффективнее использовать литературу для развития навыков чтения на уроках иностранного языка, что многажды подтверждено коллегами $[11$, с.171; 12, с. 88] для совершенствования грамматики и обогащения словарного запаса. Руководствуясь такими критериями отбора текстов, как художественный метод (предпочтительно реализм), грамматические нормы и предметно-тематическое соответствие программе курса, можно дополнять существующие и отлично зарекомендовавшие себя на протяжении нескольких десятилетий УМК («Дорога в Россию» В.Е. Антоновой, М.М. Нахабиной, М.В. Сафроновой, А.А. Толстых) произведениями русской литературы, облегчающими социализацию иностранца, а также совершенствующими его культуру и формирующими его лингвострановедческую компетенцию.

\section{ЛИТЕРАТУРА}

1. Шарафутдинова 0.И. Детская литература на уроках РКИ: к проблеме адаптации художественного текста // Проблемы преподавания филологических дисциплин иностранным учащимся. - 2010. -Т. 1. - С. 115-119.

2. Редькина 0.Ю. «Приключения незнайкии его друзей» Н. Носова на уроках PKИ // Lingua mobilis. 2016. №1 (54). URL: https://cyberleninka.ru/article/n/ priklyucheniya-neznaykii-ego-druzey-n-nosova-na-urokah-rki (дата обращения: 14.12.2020).

3. Государственный стандарт по русскому языку как иностранному. Базовый уровень. Утвержден Президиумом Совета Учебно-методического объединения вузов РФ по педагогическому образованию Министерства общего и профессионального образования Российской Федерации (заключение № 5 от 18.05.99). Издание второе, исправленное и дополненное. ... Государственный стандарт по русскому языку как иностранному. Базовый уровень / Нахабина М.М. и др. — 2 е изд., испр. и доп. - М. — СПб., 2011.

4. Фоломкина С.К. Обучение чтению на иностранном языке в неязыковом вузе. - М.: Высшая школа, 1987. С. 7.

5. Собинова Л.А. Значение когнитивных стратегий в обучении профессионально-ориентированному иноязычному чтению студентов технического вуза // Филологические науки. Вопросы теории и практики (входит в перечень ВАК). Тамбов: Грамота, 2014. № 6. Ч. 2. С. 183-186. [Электронный ресурс]. Режим доступа: https://www.gramota.net/materials/2/2014/6-2/52.html (дата обращения: 15.12.2020).

6. Джур Е.В., Куликова Т.Д., Сычева Г.П. Обучение изучающему виду чтения на занятиях по русскому языку как иностранному. // Проблемы современного педагогического образования. 2020. № 67-1. С. 81-85.

7. Kondrashova I.V. The importance of teaching different types of reading in foreign language to non-linguistic students. // International Journal of Humanities and Natural Sciences. 2020. № 5-3 (44). C. 137-140.

8. Тырхеева Н.С. Лингводидактический потенциал классического детектива на занятиях по домашнему чтению. // Проблемы современной науки и образования, № 3 (45), 2016, стр. 178-181.

9. Даниелян М.Г. Беспереводное чтение как средство обогащения речи студентов-иностранцев. // Современная наука: актуальные проблемы теории и практики. Серия «Гуманитарные науки». 2020. № 4-2. С. 76-78.

10. Уровни владения языком [Электронный ресурс]. Режим доступа: https://langformula.ru/urovni-anglijskogo-yazyka/ (дата 0бращения: 15.12.2020).

11. Волкова Е.А., Полтавцева Е.А. Организация работы по домашнему чтению студентов-инофонов начального этапа обучения РКИ. // Проблемы модернизации современного высшего образования: лингвистические аспекты. Материалы VI Международной научно-методической конференции. 2020. С. 171-174.

12. Саидова С.Я., Сафарова М.А. Чтение иноязычной литературы как универсальный инструмент формирования ключевых компетенций студентов неязыковых вузов. // Collection of scientific articles LX International correspondence scientific and practical conference. 2020. С. 88-90.

(c) Астащенко Елена Васильевна (gedda@inbox.ru), Сырова Мария Михайловна (mariya.m.syrova@mail.ru). Журнал «Современная наука: актуальные проблемы теории и практики» 